3-1-1993

\title{
A baseline study of behavioral science instruction in dental schools.
}

Brian M. Lange

University of Nebraska Medical Center, blange@unmc.edu

David G. Dunning

University of Nebraska Medical Center, ddunning@unmc.edu

Marty A. Lewis

University of Nebraska Medical Center

Tell us how you used this information in this short survey.

Follow this and additional works at: https://digitalcommons.unmc.edu/cod_articles

Part of the Dentistry Commons

\section{Recommended Citation}

Lange, Brian M.; Dunning, David G.; and Lewis, Marty A., "A baseline study of behavioral science instruction in dental schools." (1993). Journal Articles: College of Dentistry. 17.

https://digitalcommons.unmc.edu/cod_articles/17

This Article is brought to you for free and open access by the College of Dentistry at DigitalCommons@UNMC. It has been accepted for inclusion in Journal Articles: College of Dentistry by an authorized administrator of DigitalCommons@UNMC.For more information, please contact digitalcommons@unmc.edu. 


\title{
A Baseline Study of Behavioral Science Instruction in Dental Schools
}

\author{
Brian M. Lange, Ph.D.; David G. Dunning, Ph.D.; Marty A. Lewis, D.D.S. \\ Key Words: behavioral science, interpersonal communication, behavioral management, pain and anxiety control, \\ teaching methods
}

Drs. Lange and Dunning are in the Department of Dental Practice Management, and Dr. Lewis is in the Department of Pathology, Radiology, and Diagnosis, all at the University of Nebraska Medical Center, College of Dentistry, $40 t h$ and Holdrege Streets, Lincoln, NE 68583-0740. Send correspondence to Dr. Lange.

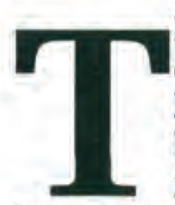

he role of human behavior in dental education has been discussed in the dental literature since the $1950 \mathrm{~s}$. As pointed out by Jackson and Katz ${ }^{1}$ the articles of the fifties tended to focus on the psychoanalytic approach to understanding human behavior. The behavioral science dental literature of the 1960 s was strongly influenced by the viewpoints of behavioral and humanistic psychology. The 1970s dental literature relating to behavioral science focused on development of curriculum content. The literature of the eighties refined curriculum content and presented behavioral science curriculum guidelines. Yet, the extent to which dental schools have incorporated behavioral sciences into their curricula is poorly documented.

The purpose of this study was to obtain a baseline of behavioral science instruction in U.S. and Canadian dental schools and thus enable faculty and administrators to compare their instruction with that of their peers. The behavioral science curricula of U.S. and Canadian schools were compared to see if a difference exists in emphasis placed on didactic, lab, and clinical hours devoted to training. A previous study revealed that U.S. and Canadian schools spent similar amounts of curriculum time on prevention. However, Canadian dental schools devoted more didactic and less clinical time to the teaching of prevention. ${ }^{2}$

\section{METHODS}

In the fall of 1990 , a survey was constructed to obtain data from dental schools on behavioral science instruction practices. The survey included background questions about the department(s) charged with primary instruction in behavioral sciences. The majority of the questionnaire asked specific questions about three broad skill or content areas: interpersonal communication, behavioral management, and pain and anxiety control. Specific skills within each of these three categories were identified from the draft of the AADS' revised curriculum guidelines in behavioral science. Interpersonal communication skills comprised 12 questions that dealt with perception, non-verbal communication, giving feedback, interviewing, listening, building relationships, assertiveness, motivating, managing conflict, case presentation, information giving, and health history taking. Behavioral management skills comprised 16 questions that dealt with principles of behavior change; influence on behavior; management of abnormal behavior; role and influence of culture; management of mentally and physically handicapped; cog. nitive and emotive management of the child, adolescent, and adult patients; and ethical issues as they relate to patient management. Anxiety and 
Table 1.

\begin{tabular}{|c|c|c|c|c|c|c|c|}
\hline & Clase Mean & Standard & Jab Mean & Standard & Clinic Mean & Standard & Total Hours \\
\hline Total Sample & 23.2 & 213 & 4.2 & 12.2 & 13.7 & 32.3 & 41.1 \\
\hline U.S. & 22.6 & 20.6 & 4.2 & 13.0 & 14.2 & 34.2 & 41.0 \\
\hline Canada & 26.1 & 26.6 & 4.1 & 6.7 & 11.0 & 20.6 & 41.3 \\
\hline \multicolumn{8}{|c|}{ Hours of Behavior Management Instruction } \\
\hline Total Sample & 34.8 & 29.0 & 2.0 & 4.1 & 13.0 & 29.8 & 49.9 \\
\hline U.S. & 33.2 & 24.1 & 2.2 & 4.4 & 13.2 & 30.6 & 48.6 \\
\hline Canada & 43.1 & 49.4 & 1.1 & 2.1 & 12.6 & 26.5 & 56.9 \\
\hline \multicolumn{8}{|c|}{ Hours of Anxiety and Pain Control Instruction } \\
\hline Total Sample & 19.9 & 21.5 & 0.8 & 1.9 & 9.7 & 25.6 & 30.5 \\
\hline U.S. & 18.1 & 17.7 & 0.8 & 1.8 & 7.5 & 24.1 & 26.5 \\
\hline Canada & 29.5 & 36.2 & 0.9 & 2.1 & 21.5 & 32.2 & 51.9 \\
\hline
\end{tabular}

pain control skills comprised nine questions that addressed instruction devoted to recognition of medication and treatment of patient anxiety, fear and pain, and treatment of phobia.

Respondents were asked to indicate the number of classroom, lab, and clinical hours devoted to each skill, whether or not students were held accountable for demonstrating the skill with patients, and the teaching methods used in holding students accountable. Respondents were also asked to indicate the types of instructional methods used in behavioral science instruction.

The detailed nature of the survey required a relatively rigorous examination of the curriculum by respondents, but the authors believed that asking respondents to indicate number of hours devoted to the three broad categories might have yielded inaccurate data estimates and would have masked potentially interesting differences regarding the instruction of specific skills.

The questionnaires were mailed to the curriculum director, dean, or behavioral/science director of dental schools in the United States, Canada, and Puerto Rico. A reminder letter was sent to schools that took longer than four weeks to respond. Second questionnaires were mailed to nonrespondents seven weeks after the original mailing.

\section{RESULTS}

Of the 65 schools surveyed, 57 responded for a return rate of 88 percent. However, six surveys were returned uncompleted. The 51 useable surveys were analyzed, yielding a return rate of 78.5 percent. Forty-three out of 55 U.S. dental schools returned useable surveys, a return rate of 78 percent. Puerto Rico was included with the U.S. dental schools in the data analysis. Eight of the 10 Canadian schools return useable surveys, a return rate of 80 percent.
A total of 39 U.S. and seven Canadian schools indicated one department had primary responsibility for teaching the behavioral science curriculum. In U.S. schools, the departments of community dentistry ( 8 ) and behavioral sciences $(6)$ were most frequently identified. Each Canadian school identified a different department.

Departments with primary responsibility for teaching behavioral science started appearing in the early $1960 \mathrm{~s}$. By the end of the decade, 10 schools had departments responsible for teaching behavioral science. The decade of the seventies witnessed rapid growth of behavioral science in the dental curriculum as evidenced by 18 schools assigning the behavioral science curriculum to departments. From 1980-90, 10 additional schools added either behavioral science departments or added behavioral science teaching responsibilities to existing departments.

U.S. and Canadian schools both offered an average of $\mathbf{4 1}$ hours of interpersonal skills instruction with some differences in classroom and clinical allocation (Table 1). The number of hours spent teaching behavior management was slightly greater overall in Canadian dental schools, where almost 10 more classroom hours of instruction were devoted to behavior management instruction. Canadian schools offered 25 hours more than U.S. schools in anxiety and pain control. Canadian schools offered considerably more classroom (11 hours) and clinical (14 hours) instruction time on the recognition and management of patient anxiety and pain.

Students in U.S. schools are held accountable for demonstrating nearly twice as many interpersonal skills ( 30 percent vs. 16 percent). U.S. students also were accountable for demonstrating a greater proportion of behavioral skills (23 percent vs. 15 percent). Students in Canadian schools are held accountable for demonstrating twice as many 
Table 2. Instructional Methods (\%)

\begin{tabular}{lccc} 
& U.S. & Canada & Total \\
\hline Lecture & 95 & 80 & 94 \\
Seminar & 77 & 63 & 75 \\
Audiotape Feedback & 23 & 25 & 24 \\
Faculty Developed Workbook & 19 & 13 & 18 \\
Videotape Feedback & 47 & 13 & 41 \\
Published Text & 42 & 13 & 37 \\
Clinical Feedback & 53 & 25 & 49
\end{tabular}

skills in pain and anxiety control (49 percent vs. 25 percent). The most prevalent method of holding students accountable was faculty observation ( 80 percent), followed by faculty evaluating audio-visual recordings of student behavior (41 percent). The third most popular accountability method involved students self-evaluating their own audiovisual recorded performances (33 percent).

The most frequently reported method of instruction used to teach behavioral science curriculum was the lecture format (Table 2). More than half of the schools responding also utilized the seminar ( 75 percent) for instruction. The use of clinical and videotape feedback and the use of published texts were considerably more frequent methods of instruction in U.S. schools.

\section{DisCUSSION}

It was clear that some uncertainty existed about what skills behavioral science includes and whether skills are taught at all or by whom. One survey respondent noted a question mark next to the interpersonal skill, assertiveness, and left the hours of instruction blank. The same person wrote this question in the margin beside a behavioral management item concerning the psychological management of patients with infectious disease: "Why is this behavioral science?" The two areas are specifically mentioned in the revised curriculum guidelines. Three other respondents indicated that other departments or faculty were thought or known to teach individual skills or groups of skills. If the respondents-those most familiar with behavioral science-are unsure of its content or if skills are taught or by whom, then it is probable that many if not most other dental educators are even more confused. Since departments or sections of behavioral science are not widespread, there may also be a sense that organizational identity and recognition are lacking in this area of dental education.

The uncertainty and lack of organizational identity may account for the fact that several institutions returned a blank survey with apologies to the effect that they simply could not readily account for the hours of behavioral science instruction in their schools. One school simply sent a school catalogue. Admittedly, the meticulous survey was somewhat burdensome to complete. Further, the results should be interpreted with some caution because of the reliance on self-report from a difficult survey.

On average, 77.9 hours of classroom teaching are given compared to seven hours in lab and 36.5 hours in the clinic. This emphasis on classroom teaching exists both in U.S. and Canadian schools. Clinical lab time receives from 29 to 38 percent of the total hours of instruction. The emphasis on the classroom raises the question about where student may learn behavioral science skills most readily. The most common personality make-up of dental students includes the MyersBriggs Type Indicator dimensions of "sensing" and "judging." 3.5 This temperament entails a preference for factual, structured, linear, concrete learning. The classroom is probably the best place for these students to learn the basic concepts, skills, and principles of behavioral science. The same students, however, will not typically be able to readily apply the concepts, skills, and principles in clinical settings without assistance from faculty. For example, a student may learn in the classroom about phobic patients and their behavior manifestations using clinical videotapes and yet try to manage a phobic patient in clinic as if the patient has normal anxiety. This may account in part for the concern that dental students have difficulty in applying classroom knowledge in a clinical setting ${ }^{6.8}$ and the 1989 AADS debate regarding whether dental students can in fact be taught interpersonal skills.?

Two issues are closely related to the concern of student ability to apply behavioral science skills: 1) the amount of time devoted to teaching specific behavioral science skills, and 2) the limited extent to which students are held accountable for demonstrating behavioral science skills with patients. As for the first issue, approximately two hours each are devoted on average to teaching students these skills: motivating patients and gaining compliance; understanding the principles of behavioral change; understanding the variables that influence patient behavior; recognizing and managing disruptive patient behavior (obsessive-compulsive, psychotic, depression, addictions); and the management of oral habit disorders. While instructors can certainly introduce students to these skills, it is doubtful that students could effectively apply them after two hours of instruction.

On average, only 37 percent of the schools appear to be using a published text. While respondents did not indicate the title of the text used, it is likely that not all 37 percent use the same text. This tendency to not use a textbook may arise because few if any textbooks address in detail the three categories surveyed-interpersonal skills, behav- 
ioral skills, and pain and anxiety control. Equally important, however, the absence of commonly used textbooks relates back to the uncertainty and lack of identity in the area of behavioral science mentioned at the beginning of the discussion.

The authors hope that behavioral science faculty will evaluate their curricula in light of these findings. Such an evaluation would include: 1) an examination of the hours devoted to the three areas and to specific skills in the AADS guidelines; 2 ) an analysis of the allocation of the instructional hours in the classroom, lab, and clinic; 3) an evaluation of the feasibility of teaching specific skills in the time provided; and 4) an evaluation of the methods used to hold students accountable, considering the utilization of perhaps more economical methods such as patient feedback and audio-visual based selfevaluation.

\section{REFERENCES}

1. Jackson E, Katz JO. Implementation of interpersonal skill training in dental schools. J Dent Educ 1983;4:66-71.

2. Lange B, Dunning D, Shea G. The Changing role of prevention in dental education. J Dent Educ 1990;54:567-9.

3. Silberman S, Cain M, Mahan J. Dental students' personality: a Jungian perspective. J Dent Educ 1982;46:646-51.

4. Erskine CG, Westerman GH, Grandy TG. Personality styles of first-year dental students. J Dent Educ 1986;50:221-4.

5. McDaniel SP, Siler WM, Isenberg BP. Analysis of personality traits of the contemporary dental student. J Dent Educ 1985;49:579-83.

6. Dunning DG, Lange BM, Adams AB. Personality type and interpersonal communication behavior of senior dental students. J Psych Type 1990;19:59-64.

7. Adams AB. The MBTI and personality type theory. Joint meeting of the section on biochemistry and nutrition and the section on physiology. 1989 AADS Annual Session, San Francisco, CA.

8. Dunning DG, Lange BM. Communication tendencies of senior dental students. J Dent Educ 1986;50:172-5.

9. Section on Behavioral Sciences. Debate: That teaching communication skills to dental students is virtually impossible. J Dent Educ 1989;53:31. 